\title{
1 Transmission risk assessment of Aedes-borne arboviral 2 diseases in Accra, Ghana
}

4 Authors: Nukunu E. Akyea-Bobi ${ }^{1}$, Jewelna Akorli ${ }^{2}$, Samuel Sowah Akporh ${ }^{1}$, Dominic Acquah5 Baidoo $^{1}$, Millicent Opoku ${ }^{2}, K_{\text {Kadwo Frempong }}^{2}$, Sellase Pi-Bansa ${ }^{2}$, Helena A. Boakye ${ }^{2}$, Joannitta 6 Joannides $^{1}$, Mufeez Abudu ${ }^{2}$, Joseph Harold Nyarko Osei ${ }^{2}$, Rebecca Pwalia ${ }^{1}$, Esinam Abla Akorli², 7 Godwin K. Amlalo르, Kofi Bonney ${ }^{3}$, Reginald Quansah ${ }^{4}$, Samuel K. Dadzie ${ }^{2 *}$

$8{ }^{1}$ Vestergaard NMIMR Vector Labs, Parasitology Department, Noguchi Memorial Institute for

9 Medical Research, University of Ghana, P.O. Box LG 581, Legon, Accra

10 2Department of Parasitology, Noguchi Memorial Institute for Medical Research, University of 11 Ghana, P.O. Box LG 581, Legon, Accra

$12{ }^{3}$ Department of Virology, Noguchi Memorial Institute for Medical Research, University of Ghana, 13 P.O. Box LG 581, Legon, Accra

$14{ }^{4}$ Department of Biological, Environmental and Occupational Health, School of Public Health, 15 University of Ghana, P.O. Box LG 13, Legon, Accra

$16 *$ Corresponding author:

17 Email: SDadzie@,noguchi.ug.edu.gh (SKD)

\section{Author email}

20 Nukunu Etornam Akyea-Bobi (NEA-B): nakyea-bobi@noguchi.ug.edu.gh

21 Jewelna Akorli (JA): jakorli@noguchi.ug.edu.gh

22 Samuel Sowa Akporh (SSA): sakporh@gmail.com

23 Dominic Aqua-Baidoo (DA-B): dabaidoo@gmail.com

24 Millicent Opoku (MO): milowuadj@yahoo.ca

25 Kwadwo Frempong (KKF): kfrempong@noguchi.ug.edu.gh

26 Sellase Pi-Bansa (SP-B): Spi-bansa@noguchi.ug.edu.gh 
27 Helena A. Boakye (HAB): hboakye@,noguchi.ug.edu.gh

28 Joannitta Joannides (JOJ): jjoannides@noguchi.ug.edu.gh

29 Mufeez Abudu (MA) : abudumufeez@gmail.com

30 Joseph Harold Nyarko Osei (JHNO): josei@noguchi.ug.edu.gh

31 Rebecca Pwalia (RP): rpwalia@noguchi.ug.edu.gh

32 Esinam Abla Akorli (EAA): eakorli@noguchi.ug.edu.gh

33 Godwin Kwame Amlalo (GKA): gamlalo@,noguchi.ug.edu.gh

34 Kofi Bonney (KB): kbonney@,noguchi.ug.edu.gh

35 Reginald Quansah (RQ): rquansah@ug.edu.gh

36 Samuel K. Dadzie (SKD): sdadzie@,noguchi.ug.edu.gh

38 Short title: Transmission of Aedes-borne virus in Ghana

39 Abstract

40 Background: Dengue, Zika and Chikungunya are Aedes-borne viral diseases that have risen to

41 become great global health concerns in the past years. Several countries in Africa have reported

42 outbreaks of these diseases and despite Ghana sharing borders with some of such countries, it

43 remains free of these outbreaks. 
44 Recent studies in Ghana have revealed that there are antibodies and viral RNA of the Dengue virus

45 serotype-2 among individuals in some localities in the Greater Accra Region. This is an indication

46 of a possible silent transmission ongoing in the population, hence the need to assess the risk of

47 transmission of these viruses within the country. This cross-sectional study, therefore, assessed the

48 risk of transmission of Dengue, Zika and Chikungunya viruses in a domestic/peri-domestic

49 (Madina) and a forest (Achimota Forest) population in the Greater Accra Region, Ghana.

50 Methodology/Findings: All stages of the Aedes mosquito (egg, larvae, pupae and adults) were

51 collected around homes and in the forest area for estimation of risk indices. All eggs and immature

52 stages were reared to adults and morphologically identified. The predominant species of Aedes

53 mosquitoes identified from both sites were Aedes aegypti (98 \% in Madina and 98.1\% in Achimota

54 forest). Aedes albopictus, an important arbovirus vector, was identified only in Madina at a

55 prevalence of $1.5 \%$ but Achimota forest had the higher species diversity. Both study sites recorded

56 high risk indices; Madina: Positive Ovitrap Index $=26.6 \%$, Container Index $=36.8 \%$, House Index

$57=19.8 \%$, Breteau Index $=70.4 \%$; Achimota: Positive Ovitrap Index $=34.2 \%$ and Container Index

$58=67.9 \%$. RT-PCR to detect the presence of Dengue, Chikungunya and Zika viruses was negative

59 for all pools tested.

60 Conclusion: All entomological risk indicators estimated showed that both sites had a high potential

61 of an outbreak of arboviral diseases following the introduction of these viruses. 


\section{Author Summary}

64 The detection of antibodies and viral RNA of the dengue virus serotype 2 in some communities in

65 the urban city of Accra, suggested the possibility of silent transmission of arboviral disease within

66 the city. We assessed the risk of arboviral disease transmission using entomological risk indices.

67 The study was a cross-sectional study conducted in a forest and peri domestic setting located in

68 the southern urban city of Accra.

69 The different stages of the Aedes mosquito were collected and, houses and containers positive for

70 Aedes mosquitoes were also noted. The Breteau (BI), House (HI), Container (CI) and Positive

71 ovitrap (POI) indices were determined. Real Time-PCR was conducted to determine the presence

72 of Dengue, Zika and Chikungunya viruses in the larvae and adults collected.

73 Aedes aegypti was the most common species identified from both sites. Aedes albopictus another

74 competent arbovirus vector was identified in the peri-domestic site. Almost all risk indices

75 recorded for both sites were higher than the WHO thresholds allowed for these indices. However,

76 real time-PCR to detect the presence of Dengue, Chikungunya and Zika viruses was negative.

77 The high entomological risk indicators estimated showed that both sites had a great potential of an

78 outbreak following the introduction of these viruses, and a well-structured surveillance for these

79 vectors is highly recommended. The detection of the presence of Ae. albopictus, an invasive

80 species is also of great concern.

\section{Introduction}


82 Dengue, Zika and Chikungunya viruses are all transmitted in urban and peri-urban areas by Aedes

83 mosquitoes of the subgenus Stegomyia. All three viruses are transmitted in zoonotic cycles

84 involving primates and mosquitoes (1). However, human activities such as the domestication of

85 the natural habitats of the reservoirs and vectors of these viruses have led to an urban transmission

86 cycle involving human-to-human transmission where Aedes aegypti and Aedes albopictus are

87 major vectors $(2,3)$.

Aedes mosquitoes are highly invasive species found on almost all continents. It has one of the

89 widest distributions ever recorded (4). Aedes aegypti is mainly found in the tropics and subtropics,

90 flourishing in domesticated environments and has adapted to feeding almost solely on humans. It

91 is active during the day and usually bites several people during the acquisition of a bloodmeal.

92 These behavioural characteristics of this mosquito combined with its high susceptibility to the

93 Dengue, Zika and Chikungunya viruses make it a very efficient vector (5).

94 Ecological and human factors seem to be strong determinants for the spread of arboviruses and

95 their vectors. The biology of the vectors, their abundance, and geographical distribution are

96 directly affected by climate (6). Global trade such as the importation of used tyres, ornamental

97 plants and used vehicles is also one of the driving factors for the spread of Aedes mosquitoes (7).

98 Infected travellers also enable the virus to reach new places within the shortest possible time (8).

99 This can lead to an explosive epidemic in areas where there is a well-established vector population.

100 Other human activities such as poor planning of urban centres leading to issues like lack of 101 consistent water supply, poor drainage and waste disposal systems also facilitate the development

102 of vectors (9); most outbreaks of arboviral diseases in Africa have occurred in urban cities (10).

103 Rapid urbanization has also been documented as one of the drivers of the spread of arboviral

104 diseases (11). 
105 In Africa, thirty-four (34) countries have reported Dengue with their capital cities being the hardest

106 hit (12). Ghana shares borders with countries (Burkina Faso, Cote d'Ivoire and Togo) that have

107 reported DENV, CHKV and ZIKV. However, Ghana has remained free of an outbreak of these

108 diseases despite Aedes aegypti mosquitoes being present in most part of the country (13-15).

109 Recent studies have revealed evidence of DENV-2 (Dengue virus serotype-2) antibodies in people

110 suspected to have malaria or visiting the hospital with acute fever symptoms $(16,17)$. The DENV-2

111 viral RNA was also detected among two children in some localities in urban Accra. Further

112 inquiries from the parents of the infected children revealed that these children had never been out

113 of the country before. This indicates that the infections were acquired locally, suggesting the virus

114 is silently circulating in the population and there may be ongoing transmission (18). This study

115 was aimed at determining the species composition, abundance, and distribution of Aedes

116 mosquitoes and estimating the risk of transmission of arboviruses within a forest and some peri-

117 urban communities in Accra, Ghana.

\section{Materials and methods}

\section{Study area}

120 The study was carried out in two sites: Achimota Eco-park (urban forest area) and Madina (peri-

121 urban community) located in the capital city of Accra Metropolis, Ghana (Fig 1). Achimota is an

122 eco-tourist site with easy access to potential visitors. The forest hosts the Accra zoo and the people

123 that frequent this eco-park originate from various parts of the country. The presence of these

124 patrons in the forest area where there are animals that serve as a reservoir of these viruses makes

125 it a probable site for DENV, ZIKV and CHKV virus circulation. 
127 Fig 1: Map of Greater Accra region showing point locations of Achimota Eco-park and

\section{Madina.}

129 Madina is an urban area which has over several years developed into a central business district 130 becoming a hub for major commercial activities. This has led to the influx of rural-urban migrants

131 looking for better prospects. Mechanic shops and tyre sale shops are common businesses found

132 within this community. These car spare parts and tyres found in these shops are imported from all

133 over the world. Due to vertical transmission of these viruses, eggs attached to these substrates

134 could potentially be carrying DENV, ZIKV and CHIKV (19). There is therefore the possibility of 135 introducing Aedes mosquitoes carrying DENV, CHKV and ZIKV into the community.

\section{Mosquito Collection}

138 The Geographical Positioning System (GPS) was recorded for each point within the study area 139 where the various stages of the Aedes mosquito were sampled using the KoBoCollect and GPS 140 Essentials app; the data was spatially displayed on a map. All collections were done within the 141 months of July-September 2020.

\section{Egg sampling}

143 A cross-sectional entomological study was carried out in the Achimota forest and Madina

144 Municipality. Ovitraps to collect Aedes eggs were prepared from plastic water bottles cut into two

145 halves and painted black on the outside. Each trap was lined with brown paper and filled with 
146 approximately $300 \mathrm{~mL}$ of hay-infused water. Each study site was divided into four quadrants and

14710 ovitraps were placed in randomly selected points per quadrant. The ovitraps were left for five

148 days to collect mosquito eggs. The traps were retrieved and replaced over three different time

149 points within the months of July-September 2020. During retrieval, the brown paper lining was

150 checked for the presence of eggs, removed from the trap and stored in labelled Ziploc bags. The

151 hay-infused water was also checked for larvae, and if any, was poured into collection bags and

152 returned to the lab. All samples were brought back to the Noguchi Memorial Institute for Medical

153 Research for further analyses. The number of eggs per trap was counted with the aid of a

154 microscope. This data was used for the estimation of the Positive Ovitrap Index (POI) and the Egg

155 Density Index (EDI). Brown paper containing eggs and the water contents of the ovitraps were

156 poured into larval trays in the laboratory and allowed to hatch. The emerging adults were identified

157 using identification keys (20).

\section{Larval and pupal sampling}

160 Potential breeding sites in and around human dwellings in the study sites were scouted for Aedes

161 larvae and pupae. The larvae and pupae collected were transported to the laboratory and counted

162 for estimations of larval risk indices; House index (HI), Container Index (CI) and Breteau Index $163(\mathrm{BI})$.

\section{Adult sampling}

165 The Biogents-sentinel traps (BG-traps) were used to capture adult Aedes mosquitoes outdoors.

166 Four (4) BG-traps were placed outside randomly selected houses and properties within a chosen

167 community in each study area. Each study site was divided into four quadrants and one BG trap 
was placed per quadrant. The collection was done over a period of 12 hours (6:00 am to 6:00 pm).

169 The adult mosquitoes caught by the trap were collected into sealed vials, transported to the

170 laboratory and stored at $-80^{\circ} \mathrm{C}$ for further analyses.

\section{Morphological Identification of Aedes mosquitoes}

172 The adult and larval stages of the Aedes mosquitoes collected from the field were morphologically

173 identified in the NMIMR entomology laboratory using morphological identification keys (Rueda,

174 2004). Identification was done with the aid of a stereomicroscope at $4 \mathrm{x}$ and $2 \mathrm{x}$ magnifications.

175 After identification, the mosquitoes were grouped into pools of 20 for the larvae and groups of 10

176 for the adults according to species. All samples were preserved in RNALater (SIGMA $\left.{ }^{\circledR}\right)$ at $-80^{\circ} \mathrm{C}$,

177 for viral detection.

\section{Viral detection using Trioplex Real-time RT-PCR Assay}

179 Each sample was homogenized in Minimum Essential Medium (MEM) containing Earle's Salts, $1802 \%$ L-glutamine, supplemented with 10\% heat inactivated FBS and Penicillin-Streptomycin. The

181 Qiagen Viral RNA mini Kit was used according to the manufacturer's instructions to extract RNA

182 from pools of mosquitoes. The AgPath-ID RT-PCR (Real-Time Reverse Transcriptase

183 Polymerase Chain Reaction) kit was used to detect DENV, CHIKV and ZIKV according to the 184 protocol by CDC (2017).

\section{Data analyses}

186 The abundance of mosquitoes and proportions of different species of Aedes mosquitoes were

187 calculated per site and compared using a Mann-Whitney test in Stata/IC 15.0. Three larval indices

188 and two ovitrap indices were used to estimate the Aedes mosquito density in both study sites. The 
189 larval indices estimated were House index (HI- the percentage of houses infested with Aedes

190 larvae or pupae), Container Index (CI- the percentage of containers infested with larvae or pupae)

191 and Breteau index (BI- the number of positive containers per 100 inspected houses). The two larval

192 indices estimated were positive ovitrap index (POI- percentage of ovitraps positive with Aedes

193 eggs) and the egg density index (EDI - average number of eggs per positive trap). All indices

194 estimated were compared to WHO thresholds for transmission risk of viral haemorrhagic fevers

195 (VHFs) to determine the risk of transmission level per index.

197 Results

198 Spatial distribution of Aedes breeding sites.

199 Maps were constructed with the recorded GPS coordinates of positive households and breeding

200 sites in the study areas to show the spatial distribution of Aedes breeding sites within the study

201 areas. Figure $2 \& 3$ shows the spatial distribution of positive breeding sites of Aedes aegypti larvae

202 relative to human habitation in Achimota Forest and Madina.

and pupae. The yellow-coloured dots show the sites of the containers found to be positive for

207 Aedes larvae and pupae. Clustered sections on the map have been expanded to clearly show the

208 distribution of the positive breeding sites. 
211 Fig 3: Spatial Map of Madina showing positive breeding sites for Aedes larvae and pupae.

212 The yellow-coloured dots indicate positive containers outside the houses, and the red dots indicate

213 houses with positive containers for Aedes larvae and mosquitoes. Clustered sections on the map

214 were expanded to clearly show the distribution of the positive breeding sites.

\section{Species abundance and composition of Aedes mosquitoes}

218 A total number of 120 ovitraps were set per study site. The total number of positive traps for

219 Achimota forest and Madina were 38 and 29, respectively. The total number of eggs counted for

220 Achimota forest and Madina was 1614 and 828, respectively. A total of 1150 larvae were collected

221 from both sites; 560 for Achimota forest and 590 for Madina. The BG traps sampled a total of 8

222 adults from Achimota forest and 28 adult mosquitoes from Madina. There was no significant

223 difference between the study areas in the number of samples collected (Fisher exact: $P>0.05$ )

224 A total of 2218 mosquitoes (adults and larvae) were identified to the species level (Fig 4). The

225 most common species of Aedes mosquitoes identified from both sites were Aedes aegypti; 98\%

226 (1148) in Madina and 98.1\% in Achimota (1027). Other species identified in Madina included

227 Aedes albopictus (1.5\%), Aedes simpsoni (0.2\%) and Aedes ingrami (0.3\%). Achimota forest

228 recorded a higher number of Aedes species; these were Aedes ingrami (0.4\%), Aedes simpsoni 
229 (0.3\%), Aedes domesticus (0.4), Aedes africanus (0.7), Aedes vittatus (0.1\%) and Aedes de-boeri

$230 \quad(0.1 \%)$

231

232

Fig 4: Species composition and abundance of Aedes mosquitoes identified from Achimota

233

forest and Madina

234

235 Larval and Ovitrap indices estimation from household surveys

236 Larval and Ovitrap indices estimated in this study were above the WHO threshold except the

237 House index in Madina which fell within the moderate risk range (Table 1). Out of 106 traps

238 retrieved per site, Achimota forest and Madina had 38 (35.9\%) and 29 (27.4\%) ovitraps positive

239 with Aedes eggs, respectively. This gave an egg density per trap of 29 in Madina and 43 in

240 Achimota forest. During the house survey, a total of 81 houses were inspected in Madina and 16

$241 \quad(19.8 \%)$ were positive for Aedes larvae. No houses were surveyed in Achimota forest because

242 there were no living quarters available. A total of 155 outdoor or peri-domestic containers were

243 inspected in Madina; 57 (36.8\%) were positive. In Achimota forest, 53 containers were inspected

244 and $36(67.9 \%)$ of these containers were found positive for Aedes larvae. Some examples of

245 containers and breeding sites that were inspected included plastic and metal barrels, buckets,

246 earthenware pots, Polytanks ${ }^{\circledR}$ (large water storage tanks), abandoned bathtubs, abandoned

247 machine parts and car tyres. Tyres were found to be the most positive containers for Aedes larvae

248 and pupae in both sites (Fig 5). 
Table 1: Larval and ovitrap indices for risk of transmission of Aedes -borne viral diseases in

250 Madina and Achimota Forest

\begin{tabular}{|c|c|c|c|}
\hline $\begin{array}{c}\text { Entomological indices for } \\
\text { study areas }\end{array}$ & Madina & $\begin{array}{l}\text { Achimota } \\
\text { Forest }\end{array}$ & $\begin{array}{c}\text { WHO Threshold for } \\
\text { transmission risk of } V H F ' s\end{array}$ \\
\hline Egg density index & 29 & 43 & NA \\
\hline Positive ovitrap index & $27.4^{*}$ & $35.5^{*}$ & $>10$ \\
\hline Container index & $36.8^{*}$ & $67.9 *$ & $3-20$ or above \\
\hline House index & $19.8^{*}$ & NA & $4-35$ or above \\
\hline Breteau index & $70.4^{*}$ & NA & $5-50$ or above \\
\hline
\end{tabular}

(*) indicates areas with high VHF transmission risk

253 Fig 5: Distribution of containers positive for Aedes larvae and pupae in Madina and 254 Achimota forest.

\section{Viral detection}

257 A total of 120 mosquito pools was tested for the presence of DENV, ZIKV and CHKV. These 258 consisted of a total of 1493 adult male and female Aedes aegypti mosquitoes and 1 pool of Aedes 259 albopictus from both study sites totalling. All the pools tested negative for DENV, ZIKV and 260 CHKV in both Achimota and Madina. 
The presence of Aedes mosquitoes have been well documented in Ghana and have been implicated

263 for the transmission of yellow fever $(13,22)$. Studies have detected the presence of antibodies and

264 viral RNA of DENV in different localities in Ghana $(16,17)$. This has emphasized the need to

265 investigate and understand the role of Aedes populations in the spread of these diseases in the

266 country, which will inform the formulation of effective and efficient strategies to prevent future

267 outbreaks or mitigate any outbreak that may arise.

268 This study focused on measuring the risk of transmission of Aedes-borne viral diseases, 269 specifically DENV, ZIKV and CHKV in a domestic (Madina) area and in a forest area (Achimota 270 forest). All stages of the mosquito were collected to detect their viral infectivity status. The most 271 abundant species of the Aedes mosquito recorded in both populations was Aedes aegypti. This 272 correlates with other studies in Ghana that have found Aedes aegypti to be the most predominant 273 (15,23). The high abundance of these vectors in the country have been attributed to the presence 274 of water holding containers close to human dwellings serving as breeding sites for these 275 mosquitoes. Aedes aegypti has over the years evolved to live close to humans and preferentially 276 choose to feed almost solely on humans even in the presence of other vertebrates that could serve 277 as host (24). Therefore, the availability of breeding sites close to human dwellings may lead to a 278 rise in the population of these Aedes species. From the spatial maps obtained for the sites, we 279 observed the proximity of positive breeding sites to houses in the area; providing evidence for the 280 high abundance of the Aedes aegypti vector. This unique characteristic of Aedes aegypti increases 281 the potential for an outbreak should the virus be introduced into these areas (25).

282 One key finding in this study was the detection of Aedes albopictus in Madina. The presence of 283 this vector has been documented before in Ghana, but this is the first time it has been recorded in 284 such relatively high numbers (26). In a previous study, very few mosquitoes were identified as 
Aedes albopictus (Suzuki et al, 2016) whilst relatively higher numbers of the species were

286 identified in this study. These mosquitoes are highly invasive species and numbers such as these

287 could be an indication of a well-established population of Aedes albopictus mosquitoes locally.

288 Aedes albopictus is another competent vector of DENV, CHKV and ZIKV and the presence of

289 two competent vectors of these viruses in Madina put the community at an even greater risk for

290 the transmission of these viruses (27-29). One important species identified in the forest area was

291 Aedes vittatus, which is known to be a principally forest and savannah species of the Aedes

292 mosquito. In some parts of Africa, Aedes vittatus has been linked to the spread of yellow fever and

293 has also been experimentally proven to spread ZIKV (30-32).

294 Water holding containers in and around homes were inspected for the presence of the aquatic 295 stages of the Aedes mosquito to allow for the estimation of the larval risk indices. Both study sites 296 recorded high values for all indices except the House index for Madina which fell within the 297 moderate risk range. These high values observed indicate a high risk of transmission should the 298 Dengue, Zika and Chikungunya viruses be introduced into these communities through the presence 299 of a positive human host, reservoir or vector. The relatively lower value observed for the House 300 index in Madina could be attributed to the use of Polytanks ${ }^{\circledR}$ (large water storage containers) and 301 plastic barrels for storage of water in the community. These water storage containers were either 302 empty or were properly covered; preventing the mosquitoes from gaining access to it as a potential 303 breeding site. The community also has regular supply of water therefore there is little need for 304 water storage.

305 Most containers found positive were observed in water holding containers outside of human 306 dwellings such as discarded bicycle and car tyres, and cans. A high number of positive tyres was 307 also recorded in the Achimota forest which were discarded near the forest office buildings. The 
308 study confirmed findings from other studies which showed that discarded tyres had a high

309 positivity rate for Aedes larvae compared to other water holding containers. This may be because

310 water collected in these tyres are left undisturbed for long periods of time. The tyres also provide

311 a dark, cool and shady environment allowing the immature stages of the Aedes mosquito to grow

312 in optimal conditions (33).

313 Adults and larvae were identified and pooled for detection of DENV, ZIKV and CHIKV. All pools

314 analysed were found negative for the viruses of interest, is in line with other studies that have been

315 conducted in other sites in Ghana $(13,22)$. Some studies have suggested that Aedes aegypti

316 mosquitoes originating from the African continent may be less competent vectors of these

317 flaviviruses $(34,35)$ because the ability of these mosquitoes to serve as competent vectors is

318 influenced by several biotic and abiotic factors. Some of these viruses are extremely vector

319 specific and some factors such as the bacterial communities associated with the vectors may

320 interfere with the ability of the virus to replicate or be transmitted (36-38). Other studies have also

321 indicated that Ghanaian strain of Aedes aegypti were refractory to infection by DENV serotype 2

322 compared to colonies from Vietnam (39).

323 Despite these reports, the Aedes mosquito population in Ghana are competent vectors of yellow

324 fever virus and findings of this study reiterate the high risk they potentially pose to transmission

325 other arboviruses. There are, however, several factors and avenues that still need to be studied to

326 fully understand the population structure and vector competence of Aedes, and the role of primate

327 reservoirs in arboviral transmission in Ghana.

\section{Conclusions}


329 The study revealed that Aedes aegypti was the most abundant species of mosquitoes in the two

330 study sites. Relatively high numbers of Aedes albopictus detected in Madina could signify the

331 establishment of a local population. Aedes mosquitoes were also observed to be breeding close to

332 human habitats. Although all pools were negative for DENV, ZIKV and CHKV, the high larval

333 and ovitrap indices recorded indicate that there is a great potential for an outbreak of these viruses

334 in both communities should they be introduced into the population through the presence of a

335 positive human host, a zoonotic reservoir or an imported positive vector. The detection of Aedes

336 vittatus also raises a cause for alarm since it has been implicated in the transmission of yellow

337 fever and has been proven experimentally to transmit ZIKV.

338 It is also recommended that a national surveillance program be put in place to monitor the species

339 abundance, diversity and risk of transmission of arboviral diseases in the country. The program

340 should also periodically screen vectors for the presence of viral infections. Further studies should

341 also be conducted in the country to test the vector competence of the Aedes species implicated in

342 the transmission of arboviral diseases. This would help in the early detection of an outbreak and

343 aid in the planning and implementation of effective and efficient control strategies.

\section{Acknowledgements}

345 We are grateful to the staff of the Department of Parasitology and Vestergaard-NMIMR Vector

346 laboratories especially Seraphim N.A Tetteh, Ibrahim K. Gyimah and Joseph Abraham for their

347 support throughout the study. We also thank staff of the NMIMR Virology department, especially

348 Eudocia Esinam Agbosu for her assistance in performing the viral detection assays. This study

349 was supported by funding from BANGA Africa-Team Research Grant (UG-BA/TRG-006/2020- 
2021) to SKD. The funders had no role in the study design, data collection and analysis, decision

351 to publish, or preparation of the manuscript.

\section{Author contributions}

353 SKD, JA, NEA-B conceptualized the study. SKD, JA, KKF, SP-B, NEA-B, KB, MO discussed

354 and designed the study. NEA-B, GKA, SSA, HAB, JHNO, RP, EAA, MO, conducted field

355 sampling. NEA-B, GKA, SSA, DA-B, MO performed laboratory experiments. SKD, RQ

356 supervised NEA-B studentship. NEA-B, JA, SKD analysed results and drafted the manuscript. All

357 authors reviewed, edited, and approved the final manuscript.

359 References

360 1. Weaver SC, Reisen WK. Present and future arboviral threats [Internet]. Vol. 85, Antiviral

361 Research. Antiviral Res; 2010 [cited 2020 Sep 14]. p. 328-45. Available from:

362 https://pubmed.ncbi.nlm.nih.gov/19857523/

363 2. Kamgang B, Vazeille M, Tedjou A, Yougang AP, Wilson-Bahun TA, Mousson L, et al.

364 Different populations of aedes aegypti and aedes albopictus (Diptera: Culicidae) from

365 Central Africa are susceptible to zika virus infection. PLoS Negl Trop Dis [Internet]. 2020

366 Mar $\quad 1 \quad$ [cited $2020 \quad$ Sep $\quad 14] ; 14(3) . \quad$ Available $\quad$ from:

367 https://pubmed.ncbi.nlm.nih.gov/32203510/

368 3. Weaver SC, Barrett ADT. Transmission cycles, host range, evolution and emergence of 369 arboviral disease [Internet]. Vol. 2, Nature Reviews Microbiology. Nature Publishing 
Group; 2004 [cited 2020 Sep 14]. p. 789-801. Available from:

www.nature.com/reviews/micro

4. Kraemer MUG, Sinka ME, Duda KA, Mylne A, Shearer FM, Brady OJ, et al. The global compendium of Aedes aegypti and Ae. albopictus occurrence. Sci Data. 2015 Jul 7;2(1):1-

5. Kamgang B, Vazeille M, Tedjou AN, Wilson-Bahun TA, Yougang AP, Mousson L, et al. albopictus (Diptera: Culicidae) populations and dengue 2 virus. PLoS Negl Trop Dis [Internet]. 2019 Dec 1 [cited 2020 Sep 14];13(12):e0007985. Available from:

6. Reinhold JM, Lazzari CR, Lahondère C. Effects of the environmental temperature on Aedes https://pubmed.ncbi.nlm.nih.gov/31887138/

7. Kilpatrick AM, Randolph SE. Drivers, dynamics, and control of emerging vector-borne zoonotic diseases. Lancet [Internet]. 2012;380(9857):1946-55. Available from:

8. Paixão ES, Teixeira MG, Rodrigues LC. Zika, chikungunya and dengue: The causes and threats of new and reemerging arboviral diseases. BMJ Glob Heal [Internet]. 2018 Jan 1 [cited 2020 Sep 10];3(Suppl 1):e000530. Available from: http://gh.bmj.com/ Singapore over the Past 40 Years: Population growth, climate and mobility. PLoS One [Internet]. 2015 Aug 31 [cited 2020 Sep 14];10(8). Available from: 
https://pubmed.ncbi.nlm.nih.gov/26322517/

393 10. Buchwald AG, Hayden MH, Dadzie SK, Paull SH, Carlton EJ. Aedes-borne disease outbreaks in West Africa: A call for enhanced surveillance. Acta Trop [Internet]. 2020 Sep

11. Rückert C, Ebel GD. How Do Virus-Mosquito Interactions Lead to Viral Emergence? Trends Parasitol [Internet]. 2018 Apr 1 [cited 2019 Oct 19];34(4):310-21. Available from: 1 [cited 2022 Jan 11];209. Available from: https://pubmed.ncbi.nlm.nih.gov/32416077/

12. Were F. The dengue situation in Africa. Paediatr Int Child Health. 2012;32(SUPP1):18-21.

13. Appawu M, Dadzie S, Abdul H, Asmah H, Boakye D, Wilson M, et al. Surveillance of Viral Haemorrhagic Fevers in Ghana: Entomological Assessment of the Risk of Transmission in the Northern Regions. Ghana Med J. 2006;40(4):137.

14. Suzuki T, Osei JH, Sasaki A, Adimazoya M, Appawu M, Boakye D, et al. Risk of transmission of viral haemorrhagic fevers and the insecticide susceptibilitystatus of aedes aegypti (linnaeus) in some sites in Accra, Ghana. Ghana Med J [Internet]. 2016 Sep 1 [cited

15. Captain-Esoah M, Kweku Baidoo P, Frempong KK, Adabie-Gomez D, Chabi J, Obuobi D, et al. Biting Behavior and Molecular Identification of Aedes aegypti (Diptera: Culicidae) Subspecies in Some Selected Recent Yellow Fever Outbreak Communities in Northern Ghana. J Med Entomol [Internet]. 2020 [cited 2020 Oct 21];57(4):1239-45. Available from:

412 16. Narkwa PW, Mutocheluh M, Kwofie TB, Owusu M, Annan A, Ali I, et al. Dengue virus 

exposure among blood donors in Ghana. J Med Biomed Sci. 2016;5(2):30-5.

414 17. Ofosu-Appiah L, Kutame R, Ayensu B, Bonney J, Boateng G, Adade R, et al. Detection of 415 Dengue Virus in Samples from Suspected Yellow Fever Cases in Ghana. Microbiol Res J 416 Int. 2018;24(1):1-10.

417 18. Amoako N, Duodu S, Dennis FE, Bonney JHK, Asante KP, Ameh J, et al. Detection of 418 dengue virus among children with suspected malaria, Accra, Ghana. Emerg Infect Dis. 2018;24(8):1561-4.

19. Ferreira-De-Lima VH, Lima-Camara TN. Natural vertical transmission of dengue virus in Aedes aegypti and Aedes albopictus: A systematic review [Internet]. Vol. 11, Parasites and Vectors. BioMed Central; 2018 [cited 2020 Oct 24]. p. 77. Available from: https://parasitesandvectors.biomedcentral.com/articles/10.1186/s13071-018-2643-9

424 20. Rueda LM. Pictorial keys for the identification of mosquitoes (Diptera: Culicidae) associated with Dengue Virus Transmission. Zootaxa. 2004;589(1):1.

426 21. CDC. Trioplex Real-time RT-PCR Assay For use under an Emergency Use Authorization only Instructions for Use. 2017.

22. Suzuki T, Osei JH, Sasaki A, Adimazoya M, Appawu M, Boakye D-I, et al. Risk of transmission of viral haemorrhagic fevers and the insecticide susceptibility status of aedes aegypti (linnaeus) in some sites in Accra, Ghana. Ghana Med J. 2016;50(503):136-41.

23. Ojukwu B, Chukwuemeka K. Ecology, distribution and risk of transmission of viral haemorrhagic fevers by Aedes mosquitoes around the port areas of Tema, southern Ghana [Internet]. University Of Ghana; 2017 [cited 2020 Oct 21]. Available from: 
24. Harrington LC, Fleisher A, Ruiz-Moreno D, Vermeylen F, Wa C V., Poulson RL, et al. Aug 7 [cited 2020 Feb 25];8(8):e3048. Available from:

25. Scott TW, Takken W. Feeding strategies of anthropophilic mosquitoes result in increased risk of pathogen transmission [Internet]. Vol. 28, Trends in Parasitology. Trends Parasitol; 2012 [cited 2020 Oct 25]. p. 114-21. Available from:

26. Suzuki T, Osei JH, Sasaki A, Adimazoya M, Appawu M, Boakye D, et al. Risk of transmission of viral haemorrhagic fevers and the insecticide susceptibilitystatus of aedes aegypti (linnaeus) in some sites in Accra, Ghana. Ghana Med J. 2016;50(3):136-41.

27. Amraoui F, Ben Ayed W, Madec Y, Faraj C, Himmi O, Btissam A, et al. Potential of Aedes https://pubmed.ncbi.nlm.nih.gov/22300806/

28. Lwande OW, Obanda V, Lindström A, Ahlm C, Evander M, Näslund J, et al. GlobeTrotting Aedes aegypti and Aedes albopictus: Risk Factors for Arbovirus Pandemics [Internet]. Vol. 20, Vector-Borne and Zoonotic Diseases. Mary Ann Liebert Inc.; 2020 2020 Sep $10]$. p. $\quad 71-81$. Available from: https://www.liebertpub.com/doi/10.1089/vbz.2019.2486 
29. Paupy C, Delatte H, Bagny L, Corbel V, Fontenille D. Aedes albopictus, an arbovirus vector: From the darkness to the light. Microbes Infect. 2009 Dec 1;11(14-15):1177-85.

30. Diagne CT, Diallo D, Faye O, Ba Y, Faye O, Gaye A, et al. Potential of selected Senegalese Aedes spp. mosquitoes (Diptera: Culicidae) to transmit Zika virus. BMC Infect Dis.

31. Sudeep AB, Shil P. Aedes vittatus ( Bigot ) mosquito : An emerging threat to public health. $2015 ; 15(1): 1-7$.

32. Weetman D, Kamgang B, Badolo A, Moyes CL, Shearer FM, Coulibaly M, et al. Aedes mosquitoes and Aedes-borne arboviruses in Africa: Current and future threats. Int J Environ Res Public Health. 2018;15(2).

33. Ferede G, Tiruneh M, Abate E, Kassa WJ, Wondimeneh Y, Damtie D, et al. Distribution and larval breeding habitats of Aedes mosquito species in residential areas of northwest

34. Bosio CF, Beaty BJ, Black IV WC. Quantitative genetics of vector competence for dengue2 virus in Aedes aegypti. Am J Trop Med Hyg. 1998;59(6):965-70.

35. Black IV WC, Bennett KE, Gorrochótegui-Escalante N, Barillas-Mury C V., FernándezSalas I, Muñoz MDL, et al. Flavivirus susceptibility in Aedes aegypti. Arch Med Res. 2002;33(4):379-88. populations from Senegal for sylvatic and epidemic dengue 2 virus isolated in West Africa. Elsevier. 2008;102:493-8. 
477 37. Lambrechts L, Minard G, Dickson LB, Volant S, Ghozlane A, Moltini-Conclois I, et al. Carryover effects of larval exposure to different environmental bacteria drive adult trait variation in a mosquito vector. Sci Adv. 2017;3(8):1-14.

480 38. Vazeille M, Yébakima A, Lourenço-de-Oliveira R, Andriamahefazafy B, Correira A, Rodrigues JM, et al. Oral Receptivity of Aedes aegypti from Cape Verde for Yellow Fever, Dengue, and Chikungunya Viruses. Vector-Borne Zoonotic Dis. 2013;13(1):37-40.

483 39. Amoa-Bosompem M, Kobayashi D, Itokawa K, Murota K, Faizah AN, Azerigyik FA, et al. 484 Determining vector competence of Aedes aegypti from Ghana in transmitting dengue virus serotypes 1 and 2. Parasites and Vectors [Internet]. 2021 Dec 1 [cited 2022 Jan 11];14(1):1- 
Figure 1

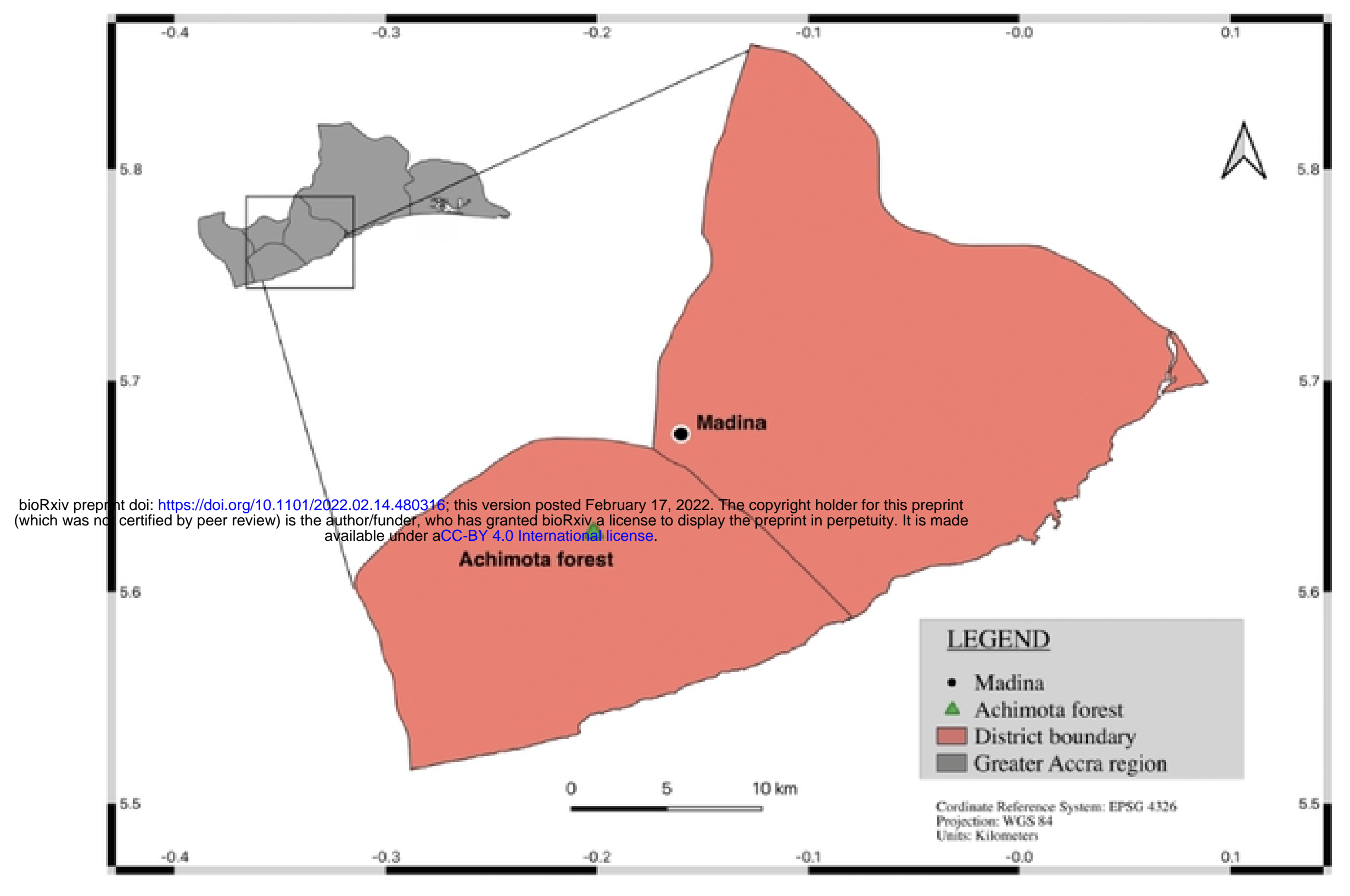

Figure 1 
Figure 2
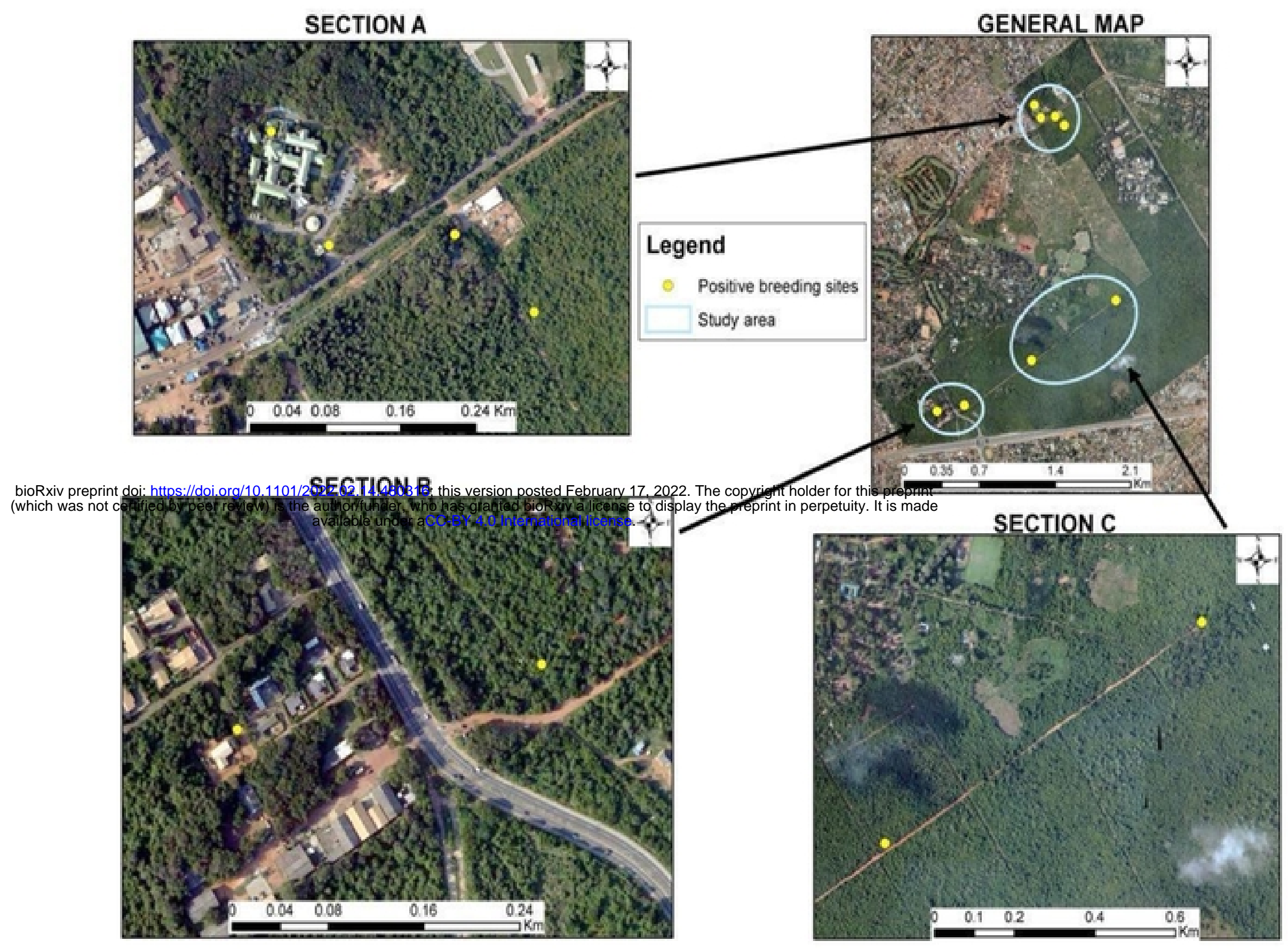

Figure 2 
Figure 3
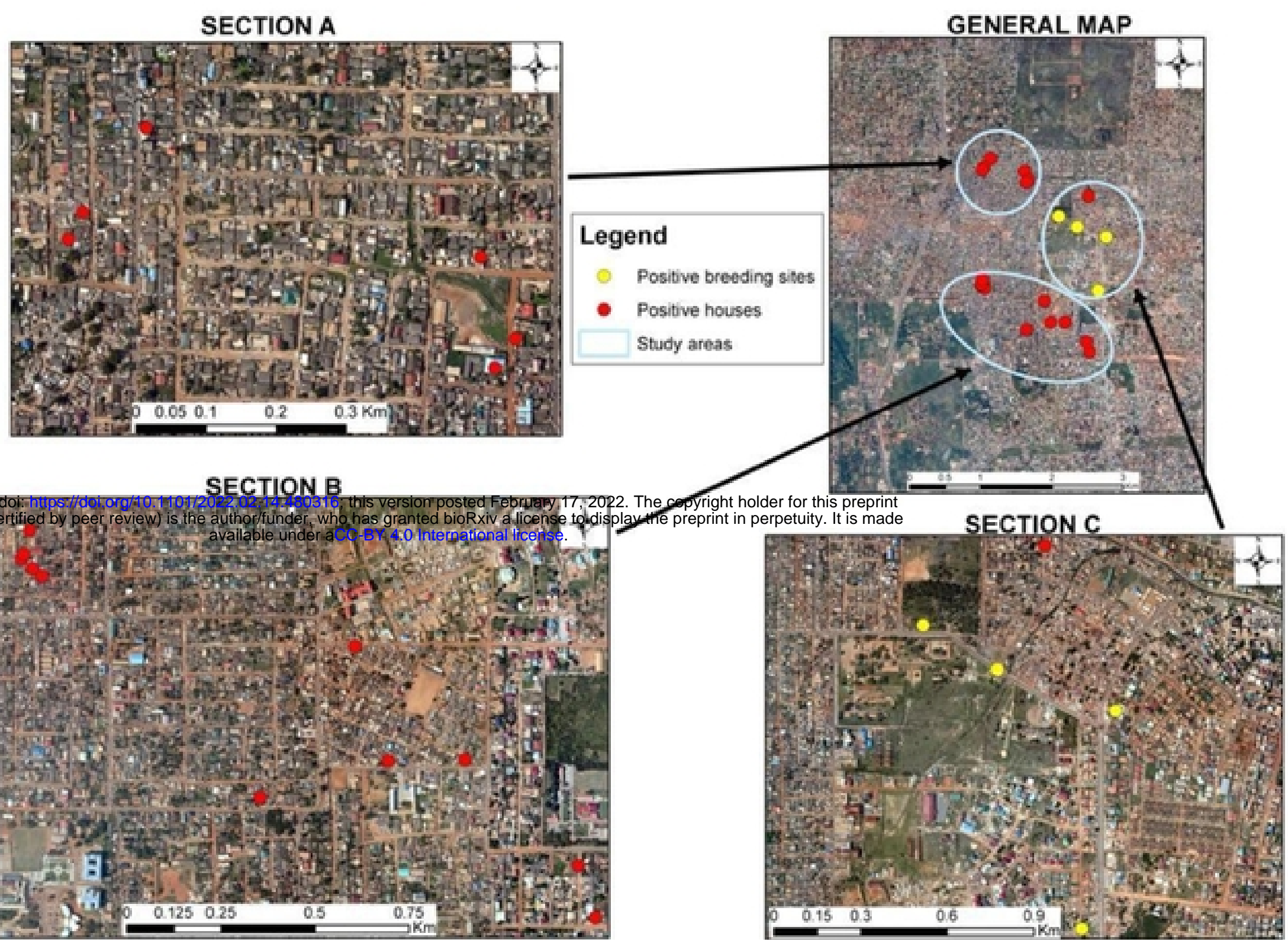

Figure 3 
Figure 4

Species composition and Abundance

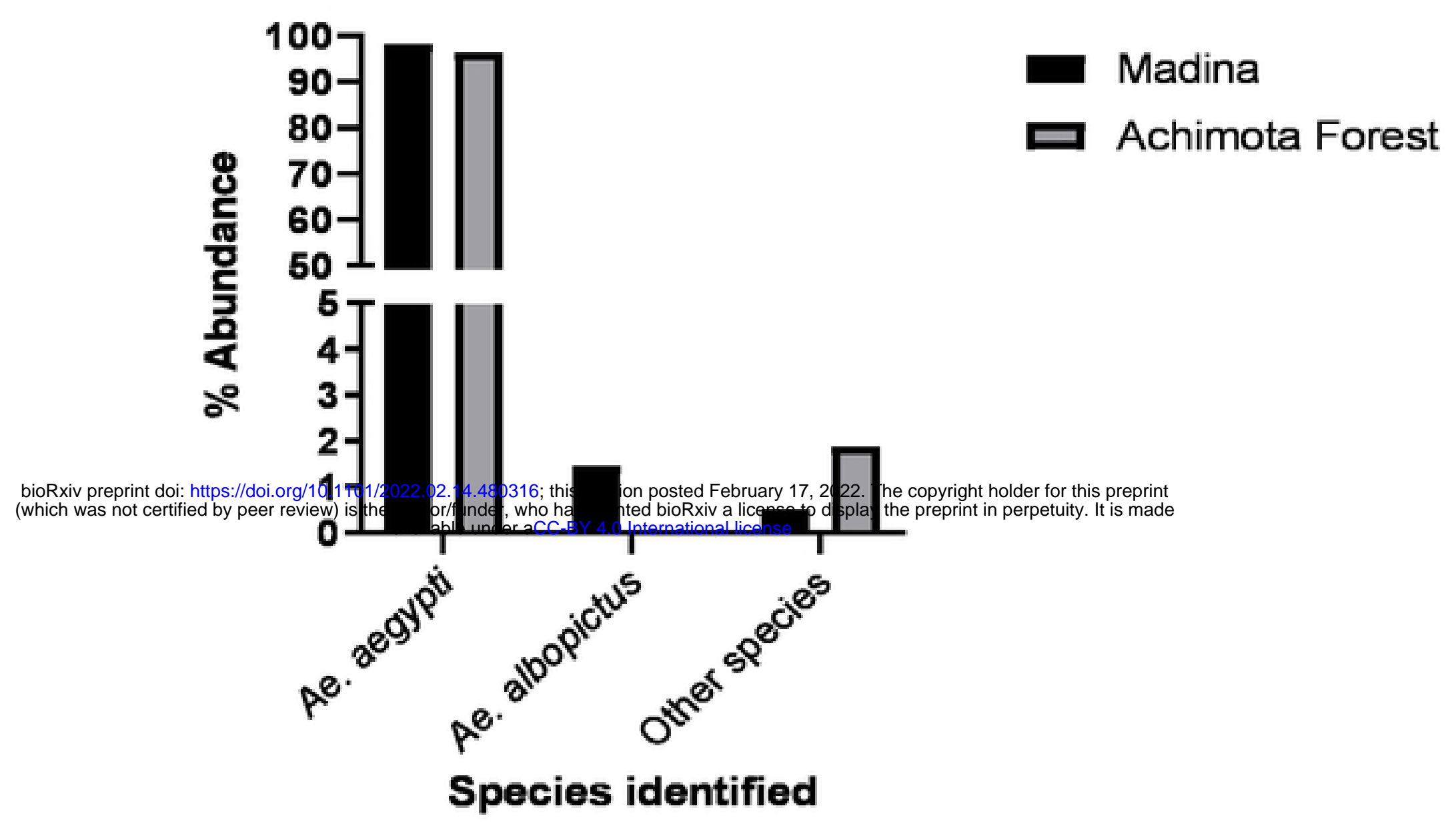

Figure 4 


\section{Figure 5}

Containers positive for Aedes Larvae in Achimota

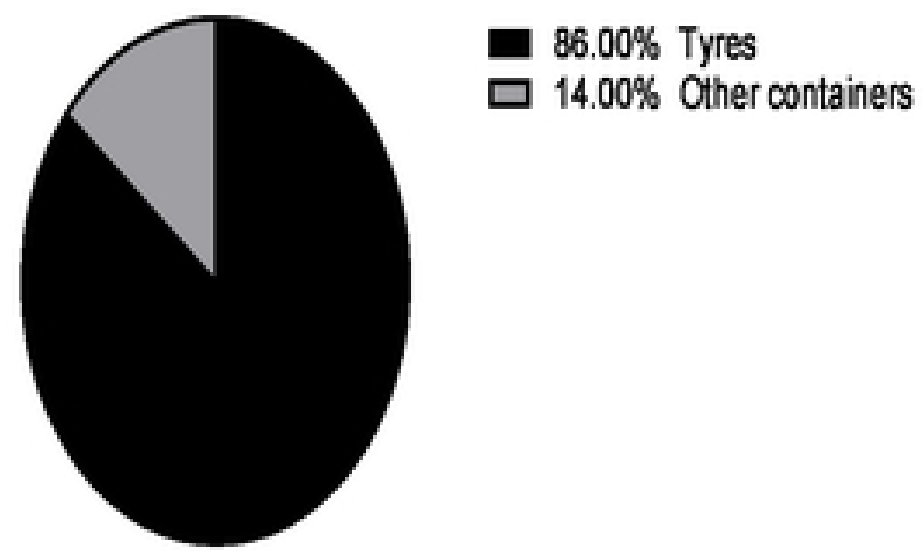

Containers positive for Aedes Larvae in Madina

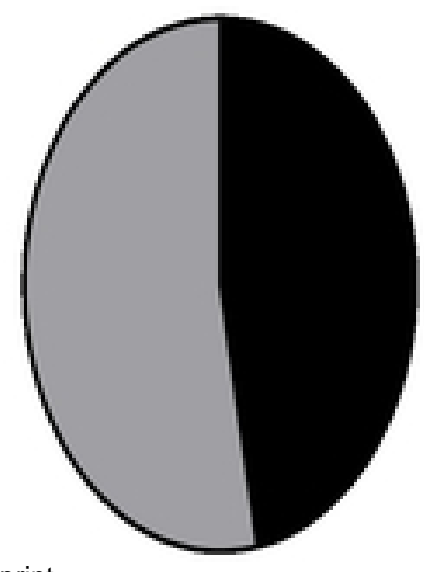

- $47.00 \%$ Tyres

ㅁ $53.00 \%$ Other contain

bioRxiv preprint doi: https://doi.org/10.1101/2022.02.14.480316; this version posted February 17, 2022. The copyright holder for this preprint

\section{Figure 5}

